\title{
Ion exchange chromatography of purified colonic mucus glycoproteins in inflammatory bowel disease: absence of a selective subclass defect
}

\author{
A Raouf, N Parker, D Iddon, S Ryder, B Langdon-Brown, J D Milton, R Walker, J M Rhodes
}

\begin{abstract}
Previous reports of a selective mucin subclass defect in ulcerative colitis have been reassessed using high performance chromatography (Superose 6 and Mono Q) for mucin purification and fractionation coupled with analysis of the fractions obtained using a combination of enzyme linked lectin and mucin antibody assays. Mucin samples purified from snap frozen rectal biopsy specimens obtained from patients with ulcerative colitis $(n=12)$, Crohn's disease $(n=5)$, and non-inflammatory bowel disease control subjects $(n=9)$ were subject to ion exchange chromatography using a continuous $0-0.35 \mathrm{~mol} / / \mathrm{NaCl}$ salt gradient with a final $2.5 \mathrm{~mol} / 1 \mathrm{NaCl}$ step. In all samples the major proportion (mean (SD) $86.7(8.9) \%$ ) of the mucin detectable by wheat germ agglutinin binding eluted between 0.15 and $0.35 \mathrm{~mol} / 1 \mathrm{NaCl}$ with no significant difference in elution profile between ulcerative colitis and control subjects. Significant elution of glycoprotein at $<0.15 \mathrm{~mol} / 1 \mathrm{NaCl}$ did occur, however, when a lower molecular weight mucin containing fraction which contained concanavalin A positive (glucose or mannose containing) material was analysed similarly. Similar ion exchange profiles were obtained when $\left({ }^{3} \mathbf{H}\right) \mathbf{N}$-acetylglucosamine labelled mucins were studied after tissue culture of rectal biopsy specimens. No significant alteration in the ion exchange profile of purified mucins in ulcerative colitis has been shown in these studies. It is possible that the previously reported relative depletion of mucin subclass IV (eluting with $0.20 \mathrm{~mol} / 1 \mathrm{NaCl}$ ) may simply have reflected mucin depletion.
\end{abstract}

Considerable interest has been stimulated by the report of a selective depletion of a colonic mucin subclass in ulcerative colitis' ${ }^{1}$ which persists even in remission. ${ }^{2}$ This report was based on analysis of purified mucus glycoprotein (mucin) by ion exchange chromatography using a discontinuous salt gradient with six salt steps, each of which eluted a mucin fraction demoted by the numerals I-VI. Fraction IV eluting with $0.20 \mathrm{~mol} / 1 \mathrm{NaCl}$ was found to be depleted in ulcerative colitis. The importance of this finding depends on knowing whether all six fractions truly consisted of mucin or whether some might have represented the non-mucus glycoproteins which are notoriously difficult to exclude during mucin purification. LaMont and Ventola had previously applied the same technique to fractionation of rat colonic mucin but had interpreted their results differently. ${ }^{3}$ They found that fraction II was of much lower molecular weight and contained glucose, which is not a component of mucin, and mannose, which should be present only in trace amounts, and speculated that this fraction migh contain fragments of the mucin granule membrane. Fraction III also contained mannose and presumably represented tissue glycoprotein while fraction VI, which eluted with the final $5 \cdot 0$ $\mathrm{mol} / \mathrm{l} \mathrm{NaCl}$ step, contained DNA. They concluded that mucin eluted in fractions IV and V. This is supported by tissue culture experiments on human colonic biopsy specimens reported by Cope $e t a l^{4}$ in which radiolabelled glucosamine incorporated in purified mucins was detectable predominantly in the fractions eluting at $0 \cdot 20$ $0.25 \mathrm{~mol} / 1 \mathrm{NaCl}$. If fractions IV and $\mathrm{V}$ contain virtually all the mucin the depletion of subclass IV relative to the other eluted glycoprotein fractions could simply reflect the mucus depletion that is well known to occur in ulcerative colitis even in remission.

It should also be realised that the division into six subclasses is arbitrary and reflects the number of steps in the discontinuous salt gradient. A different profile is obtained when a continuous salt gradient is used. ${ }^{6}$ Although the discontinuous gradient may be useful for preparation of mucin fractions, analysis of the elution profile is much easier if a continuous gradient is used.

Whenever abnormal biochemistry, physiology, or immunology is shown in inflammatory bowel disease it is always difficult to distinguish cause and effect. When studying mucus biochemistry, samples should ideally be obtained from patients in complete remission, and this means that techniques have to be developed which allow detection and analysis of the very small amounts of mucin extractable from small biopsy specimens. One solution is in vitro radiolabelling of the mucin carbohydrate,,$^{27}$ but there must be a possibility that the radiolabelling process itself may cause alterations in the mucin biochemistry. An alternative approach is to use a panel of enzyme linked lectins with different carbohydrate specificities as a highly sensitive method for analysing and quantifying small amounts of glycoprotein. ${ }^{8}$

Recently, improvements in manufacturing techniques have resulted in the availability of uniformly sized chromatography beads which allow much higher quality separation than polydisperse beads. ${ }^{9}$ Highly purified mucin can be prepared in a single chromatographic step. In the study reported here this technique has been combined with lectin analysis to reassess the ion exchange profile of purified mucins in ulcerative colitis and control specimens. 


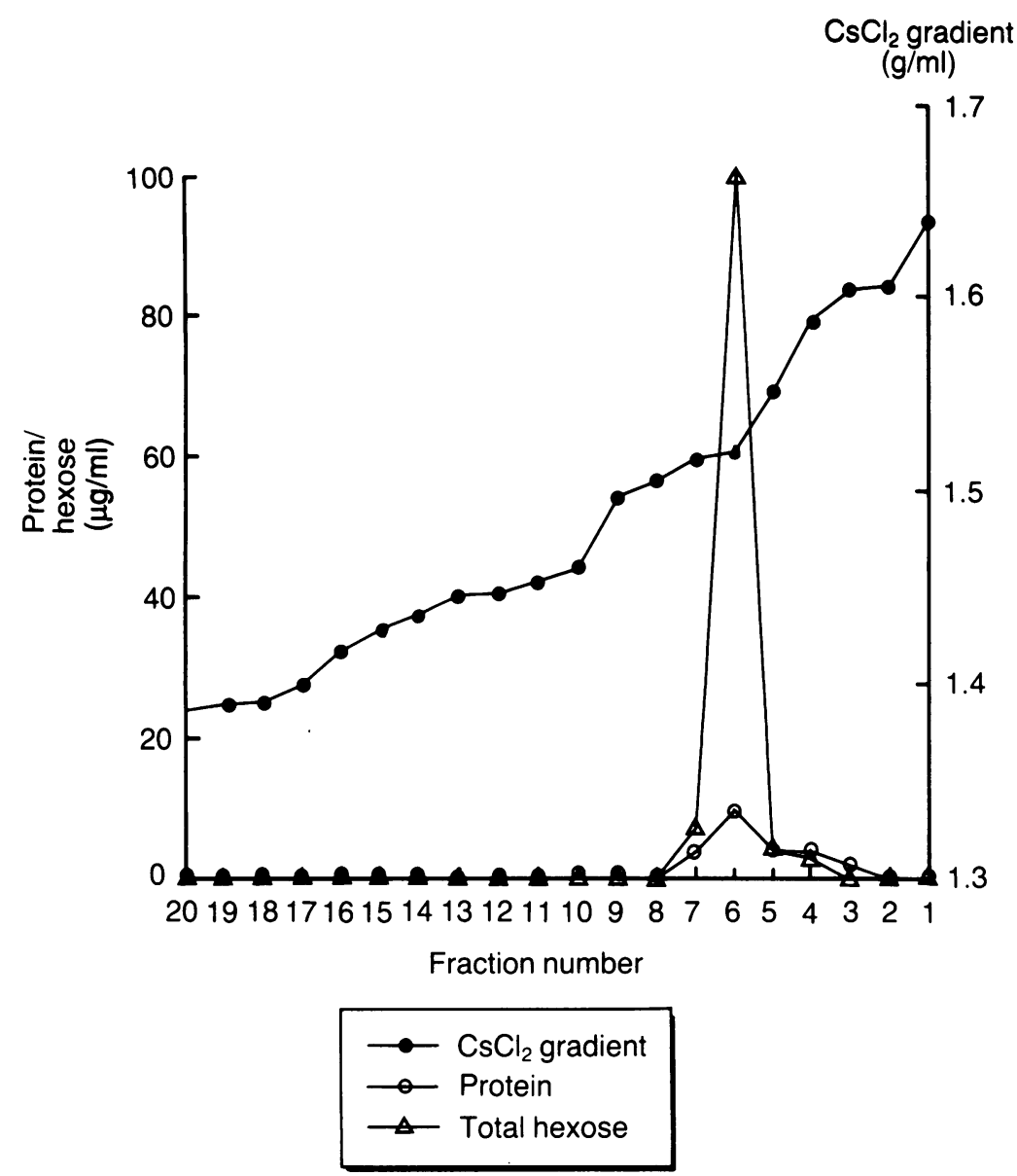

Figure 1: Caesium chloride density gradient centrifugation of mucin (protein content $40 \mu \mathrm{g}$ ) from histologically normal colon after purification on monodisperse cross-linked agarose (Superose 6) showing absence of low density glycoprotein. lyophilised, and reconstituted in $0.2 \mathrm{ml} 0 \cdot 1 \mathrm{~mol} / \mathrm{l}$ Tris $\mathrm{HCl} \mathrm{pH} \mathrm{8 \cdot 0.}$

The crude mucin sample was injected via a $200 \mu \mathrm{l}$ sample loop onto a $10 \mathrm{~mm} \times 300 \mathrm{~mm}$ gel filtration column containing monodisperse cross-linked agarose beads (Superose 6, Pharmacia, Uppsala, Sweden) and eluted using $0.1 \mathrm{~mol} / 1 \mathrm{Tris} \mathrm{HCl} \mathrm{pH} 8.0$ at a flow rate of 0.25 $\mathrm{ml} / \mathrm{min}$ with continuous optical density monitoring at $280 \mathrm{~nm}$ and collected in $100 \times 0.5 \mathrm{ml}$ samples. The fraction corresponding to the initial optical density peak was confirmed as mucin by immunoassay using an antimucin monoclonal antibody (see later) and by Alcian blue staining of a 'dot blot' on nitrocellulose paper. Parallel studies performed on five control specimens to determine yield showed that specimens with an average wet weight of $10.4 \mathrm{mg}$ yielded an average of $718 \cdot 2 \mu \mathrm{g}$ protein (modified Lowry, see below) in the supernatant after ultrasonication and centrifugation and $40.2 \mu \mathrm{g}$ protein of pure mucin after high performance gel filtration. Recovery from the Superose 6 column was tested using $\left({ }^{3} \mathrm{H}\right) N$-acetylglucosamine radiolabelled pure mucin and found to be $96 \cdot 4 \%$. Previous studies had shown that mucin prepared in this way is free from non-mucus glycoprotein or proteins as judged by caesium chloride density gradient centrifugation and sodium dodecylsulphate-polyacrylamide gel electrophoresis (Figs 1 and 2).

\section{ION EXCHANGE CHROMATOGRAPHY}

Purified mucin in $0 \cdot 1 \mathrm{~mol} / \mathrm{l}$ Tris $\mathrm{NCl}$ pH 8.0 (30 $100 \mu \mathrm{g}$ protein content estimated by a modified Lowry assay) ${ }^{10}$ was applied to a $5 \mathrm{~mm} \times 50 \mathrm{~mm}$ ion exchange column containing monodisperse beads (mono Q, Pharmacia, Uppsala, Sweden) and eluted at $1 \mathrm{ml} / \mathrm{min}$ using the same buffer with a continuous salt gradient $0-0.35 \mathrm{~mol} / \mathrm{l}$ $\mathrm{NaCl}$ and a final $2.5 \mathrm{~mol} / \mathrm{l} \mathrm{NaCl}$ step. Forty four $\times 1 \mathrm{ml}$ fractions were collected. Recovery from the mono $Q$ column was checked using $\left({ }^{3} \mathrm{H}\right) \mathrm{N}$-acetylglucosamine radiolabelled pure mucin and found to be $95 \cdot 1 \%$. frozen in liquid nitrogen. Among the patie with ulcerative colitis eight had macroscopic evidence of active disease seen at colonoscopy, while four were macroscopically normal. Histological assessment of biopsy specimens taken from adjacent tissue showed appreciable acute inflammation in four and mucus depletion in six. The patients with Crohn's disease all had ileocolonic involvement but no macroscopic rectal disease. The control subjects were five patients with solitary colonic polyps and four with unexplained iron deficiency anaemia without colonoscopic abnormality.

Biopsy specimens (mean wet weight $6 \mathrm{mg}$ ) were thawed, washed, and ultrasonicated in the presence of a cocktail of protease inhibitors (phenylmethylsulfonyl fluoride $1 \mathrm{mmol} / \mathrm{l}$, ethylenediamine tetra-acetate $10 \mathrm{mmol} / \mathrm{l}$, iodoacetamide $4 \mathrm{mmol} / \mathrm{l}$, benzamidine hydrochloride $5 \mathrm{mmol} / \mathrm{l}, N$-ethyl maleimide $5 \mathrm{mmol} / \mathrm{l}$, caproic acid $100 \mathrm{mmol} / \mathrm{l}$, and epoxy phenoxy propane $5 \mathrm{mmol} / \mathrm{l})$. Ultrasonication was by $8 \times 15$ second bursts using an MSE ultrasonicator (No 4 power setting). This was followed by centrifugation at $110000 \mathrm{~g}$ for 90 minutes and the supernatant was dialysed extensively against deionised water,

\section{IMMUNOASSAY AND ENZYME LINKED LECTIN}

\section{BINDING ASSAY OF MUCIN FRACTIONS}

The mucin fractions were subjected to analysis by enzyme linked lectin binding assay using peroxidase linked wheat germ agglutinin $(N$ acetylneuraminic acid and $N$-acetylglucosamine binding), limax flavus agglutinin ( $N$-acetylneuraminic acid binding), and concanavalin A (mannose and glucose binding). Lectins were obtained from E-Y, San Mateo, USA.

Mucin immunoassays were performed on all samples using an antimucin mouse monoclonal antibody, CAM 17.1, and another assay was performed in addition on five of the contro samples using a mouse antimucin monoclonal antibody (MMM 17) that we had prepared by immunisation with purified normal human colonic mucin. MMM 17 has been shown on immunohistochemistry to have high specificity and strong binding to colonic mucin regardless of $\mathrm{ABH}$ or Lewis blood group (Dr J Bara, personal communication) and has specificity for 

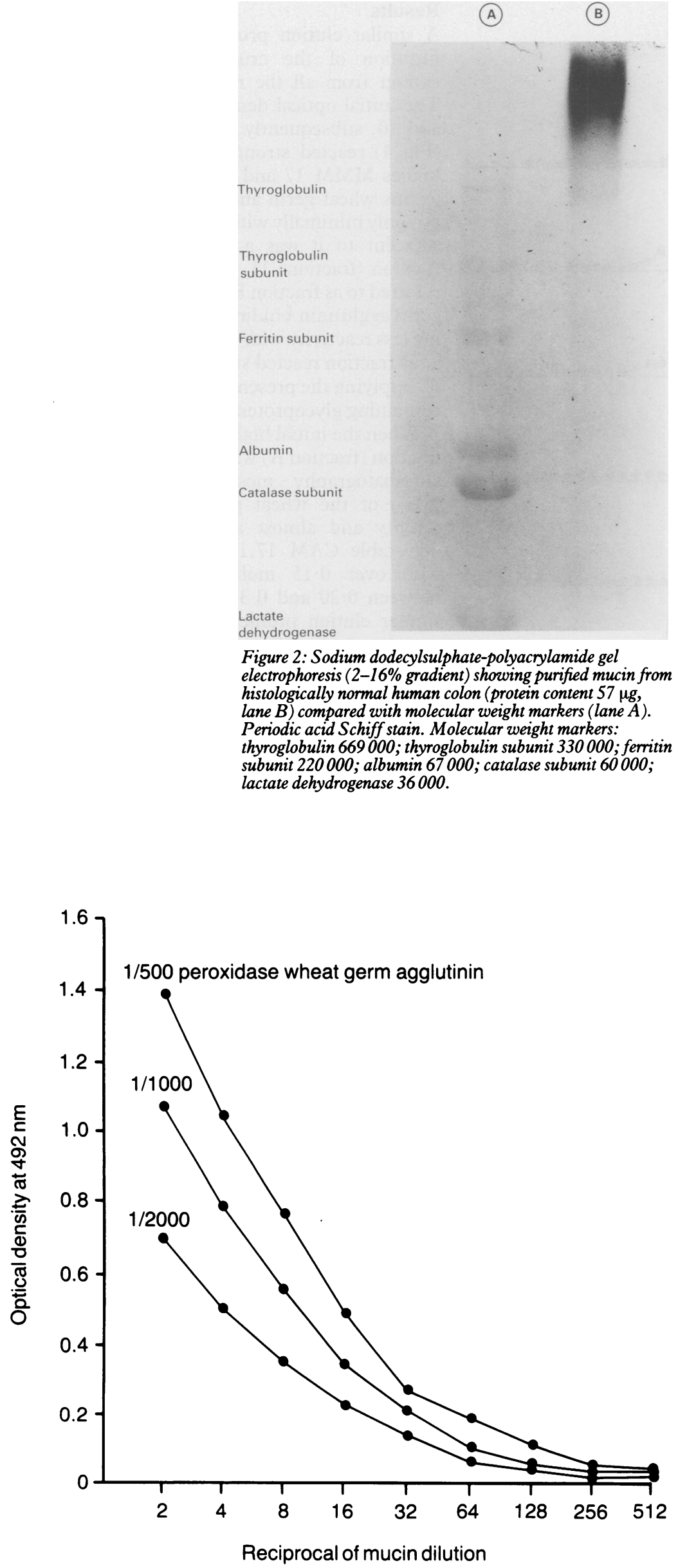

Figure 3: Peroxidase linked wheat germ agglutinin binding assay. Effects of serial dilution of normal human colonic mucin and conjugated lectin; $1 / 1000$ peroxidase-wheat germ agglutinin is equivalent to $1 \mu \mathrm{g} / \mathrm{ml}$ lectin protein. sulphated mucins (in preparation). CAM 17.1 was developed at the Imperial Cancer Research Fund and generously donated by $\operatorname{Dr} C$ A Makin. It was developed after inoculation with extracts from human meconium, a colorectal cancer cell line, and a colorectal adenoma cell line." It has been shown by immunohistochemistry and red cell agglutination studies to have blood group reactivity which is still being further characterised. It agglutinated all of a large panel of adult donor red cells but failed to agglutinate cord red cells and its binding to tissue and red cells is appreciably diminished by sialidase treatment (in preparation).

Cobalt irradiated enzyme linked immunosorbent assay ELISA plates (Dynatech, Billingshurst, UK) were coated by incubation with $50 \mu \mathrm{l}$ aliquots of the mucin fractions diluted $1: 2$ in carbonate buffer $\mathrm{pH} 9 \cdot 6$ for 16 hours at $4^{\circ} \mathrm{C}$. Coating with carbonate buffer alone was used as control. Unbound material was then removed by three washings with $0.1 \mathrm{~mol} / \mathrm{l}$ phosphate buffered saline (PBS) $\mathrm{pH} 7 \cdot 2 /$ Tween 20 $(0 \cdot 1 \%)$, followed by quenching using the same buffer for one hour at room temperature. The peroxidase-tagged lectin $(50 \mu \mathrm{l}$ containing $1.67 \mu \mathrm{g} / \mathrm{ml})$ or antimucin antibody $(100 \mu \mathrm{l}$ CAM 17.1 or MMM 17 tissue culture supernatant) was then added, followed by incubation at $37^{\circ} \mathrm{C}$ for two hours and washing off of the unbound lectin or antibody. Bound CAM 17.1 or MMM 17 was detected by incubation with peroxidase labelled rabbit antimouse IgM (Sigma, USA) at 1:600 dilution in PBS/Tween 20 $\mathrm{pH} 7 \cdot 2$ for two hours at $37^{\circ} \mathrm{C}$, followed by further washing to remove unbound second antibody. Peroxidase activity was shown by addition of $200 \mu \mathrm{l}$ orthophenyldiamine (OPD)/ $\mathrm{H}_{2} \mathrm{O}_{2}$ (containing $0.4 \mathrm{mg} / \mathrm{ml} \mathrm{OPD}$ and $1.6 \mu \mathrm{l} / \mathrm{ml} \mathrm{H}_{2} \mathrm{O}_{2}$ in phosphate citrate buffer $\mathrm{pH} 5 \cdot 0$ ). The reaction was stopped after 30 minutes by the addition of $100 \mu 14 \mathrm{~mol} / \mathrm{l}$ sulphuric acid and optical density read at $492 \mathrm{~nm}$ (CSL 962, Cambridge, UK).

Checkerboard assays had previously been performed to establish the optimum conditions for each assay (Fig 3). Reproducibility for the wheat germ agglutinin binding assay was satisfactory with a coefficient of variation of $8 \cdot 7 \%$ between plates, CAM 17.1 binding assay coefficient of variation $10.3 \%$ between plates, and MMM 17 binding assay coefficient of variation $7 \cdot 9 \%$ between plates.

\section{PROTEIN ASSAY}

Protein assay was performed using a modified Lowry technique ${ }^{10}$ in which the sample being tested was treated with sodium deoxycholate and precipitated with trichloroacetic acid before assay. A standard curve was performed with each assay using serial dilutions of purified bovine submaxillary mucin (Sigma) of known protein content. Coefficient of variation for the assay was $8 \cdot 4 \%$ and sensitivity $5 \mu \mathrm{g}$ mucin protein.

\section{INCORPORATION OF $\left({ }^{3} \mathrm{H}\right) N$-ACETYLGLUCOSAMINE} IN TISSUE CULTURE

Rectal biopsy specimens from a further five patients with ulcerative colitis, two patients with 


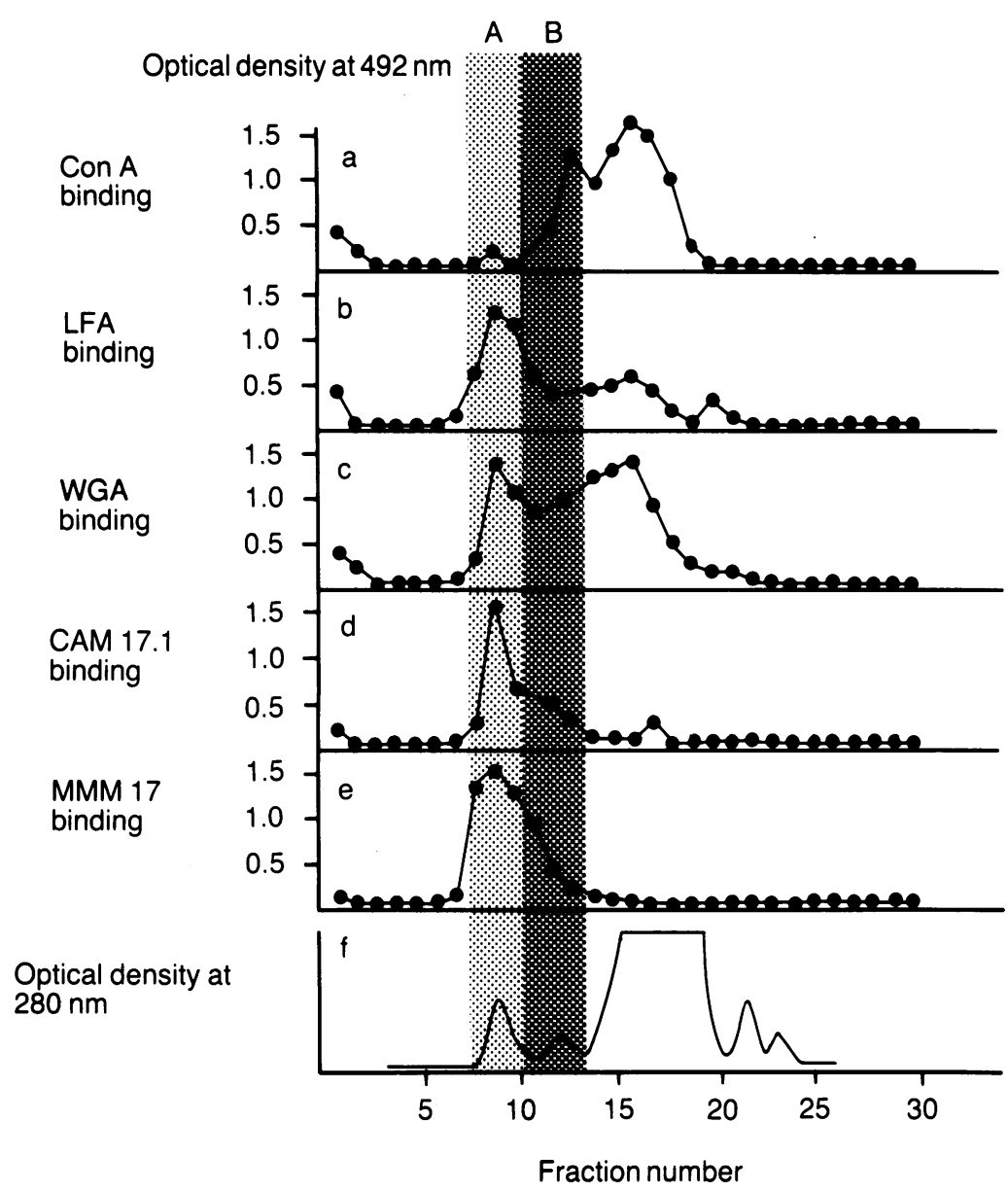

Figure 4: Superose 6 gel filtration elution profile of water soluble glycoproteins extracted from a normal rectal biopsy specimen with analysis by (a) concanavalin A binding; (b) limax flavus agglutinin binding; (c) wheat germ agglutinin binding; $(d) C A M 17.1$ mucin monoclonal antibody binding; (e) MMM 17 antimucin monoclonal antibody binding; and $(f)$ continuous monitoring of optical density at $280 \mathrm{~nm}$.

\section{Results}

A similar elution profile was obtained on gel filtration of the crude soluble glycoprotein extract from all the rectal specimens studied. The initial optical density peak (fractions 8, 9, and 10 , subsequently referred to as fraction $\mathrm{A}$ (Fig 4) reacted strongly with the mucin antibodies MMM 17 and CAM 17.1 and with the lectins wheat germ and limax flavis agglutinins but only minimally with concanavalin A. Eluting adjacent to it was a lower molecular weight fraction (fractions 11,12 , and 13 subsequently referred to as fraction B (Fig 4) containing wheat germ agglutinin binding glycoprotein but showing less reactivity with MMM 17 and CAM 17.1. This fraction reacted strongly with concanavalin A, implying the presence of mannose or glucosecontaining glycoprotein.

When the initial high molecular weight mucin fraction (fraction A) was subject to ion exchange chromatography most $(86.7 \quad(8.9) \%$, mean (SD)) of the wheat germ agglutinin binding activity and almost all $(96 \cdot 1(3 \cdot 6) \%)$ of the detectable CAM 17.1 binding activity eluted with over $0.15 \mathrm{~mol} / 1 \mathrm{NaCl}$, predominantly between 0.20 and $0.35 \mathrm{~mol} / 1 \mathrm{NaCl}$ (Fig 5). A similar elution profile was obtained in all the samples studied from patients with ulcerative colitis and Crohn's disease and control subjects (Table).

The lower molecular weight concanavalin A reactive fraction (fraction $B$ ) from nine samples (four ulcerative colitis, two Crohn's disease, and three control) was also subject to ion exchange chromatography and this showed a different profile. CAM 17.1 binding activity still eluted between 0.20 and $0.35 \mathrm{~mol} / 1 \mathrm{NaCl}$ but 43.6 $(8 \cdot 6) \%$ (mean $(\mathrm{SD})$ ) of the wheat germ agglutinin binding glycoprotein eluted between 0 and $0 \cdot 20$ $\mathrm{mol} / \mathrm{l} \mathrm{NaCl}$ as two distinct peaks eluting at $0 \cdot 1$ $\mathrm{mol} / \mathrm{l}$ and $0.15 \mathrm{~mol} / \mathrm{l} \mathrm{NaCl}$ (Fig 6). The glycoprotein fractions eluting at low salt concentrations were, however, bound by concanavalin $\mathrm{A}$, implying the presence of glucose or mannosecontaining glycoproteins which may be nonmucus glycoproteins. A similar elution profile for fraction B was again observed in ulcerative colitis, Crohn's disease, and control specimens. Immunoassays with CAM 17.1 and MMM 17 yielded similar elution profiles.

Similar results were obtained from studying $\left({ }^{3} \mathrm{H}\right) N$-acetylglucosamine incorporation into mucus by rectal specimens in tissue culture with mucin contained in fraction $A$ eluting almost exclusively at $>0.2 \mathrm{~mol} / 1 \mathrm{NaCl}$ in ulcerative colitis and control specimens (Fig 7a) while considerable $\left({ }^{3} \mathrm{H}\right) N$-acetylglucosamine eluted at lower salt concentrations as three distinct peaks when the lower molecular weight fraction B was studied (Fig 7b).

\section{Discussion}

In this study purified colonic mucus glycoprotein has been shown to elute almost entirely above $0.15 \mathrm{~mol} / 1 \mathrm{NaCl}$ when subject to ion exchange chromatography, with no difference in the elution profile obtained in ulcerative colitis, Crohn's disease, or control specimens. The discrepancy between this finding and previous
$\mathrm{NaCl}$ in patients and control subjects (mean $(S D)$ )

\begin{tabular}{llll}
\hline & $\begin{array}{l}\text { Control subjects } \\
(n=9)(\%)\end{array}$ & $\begin{array}{l}\text { Ulcerative colitis } \\
\text { patients } \\
(n=12)(\%)\end{array}$ & $\begin{array}{l}\text { Crohn's disease } \\
\text { patients } \\
(n=5)(\%)\end{array}$ \\
\hline $\begin{array}{l}\text { Wheat germ agglutinin binding activity } \\
\text { eluting at }>0.15 \mathrm{~mol} / \mathrm{NaCl}\end{array}$ & $81.9(12 \cdot 9)$ & $88 \cdot 8(5 \cdot 2)$ & $\mathbf{8 9 \cdot 2 ( 3 . 4 )}$ \\
$\begin{array}{l}\text { CAM } 17.1 \mathrm{binding} \mathrm{activity} \mathrm{eluting} \mathrm{at} \\
>0.15 \mathrm{~mol} / \mathrm{NaCl}\end{array}$ & $95 \cdot 3(2 \cdot 8)$ & $96 \cdot 1(4 \cdot 2)$ & $97 \cdot 7(2 \cdot 9)$ \\
\hline
\end{tabular}


Optical density read at $492 \mathrm{~nm}$

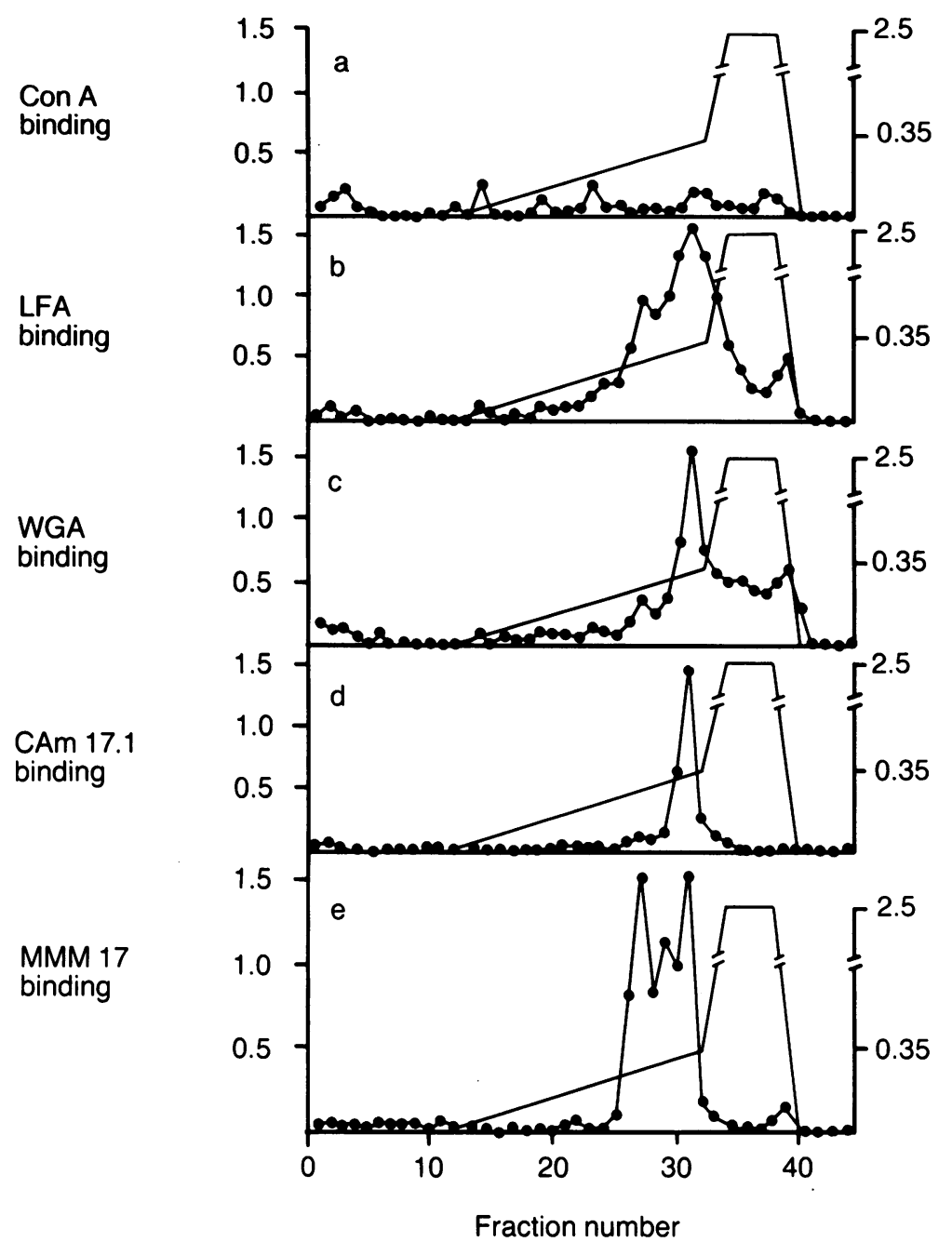

Figure 5: Ion exchange chromatography of purified normal rectal mucus glycoprotein (fraction $A$, see Fig 1) with analysis by (a) concanavalin A binding; (b) limax flavus agglutinin binding; (c) wheat germ agglutinin binding; (d) CAM 17.1 antimucin monoclonal antibody binding; and (e) MMM 1 antimucin monoclonal antibody binding. work $^{12}$ probably reflects differences in the techniques used for mucin purification. The monodisperse agarose beads used for the preparative gel filtration in this study give greater separation than conventional polydisperse beads. Using this system it has proved possible to separate a lower molecular weight fraction (fraction B) that contains concanavalin A-binding material (probably mannose) as well as mucus glycoprotein identifiable by antimucin monoclonal antibody binding and Alcian blue positivity. Some of this lower molecular weight fraction elutes at lower salt concentrations corresponding approximately to the previously described fractions I, II, and III. These fractions had been found to contain only minimal mannose by direct measurement but the concanavalin A binding assay is likely to have greater sensitivity for the detection of mannose, which probably explains this apparent discrepancy. The nature of this mannose-containing glycoprotein is unclear. Mucin has generally been regarded as being virtually mannose free $(<1 \mathrm{~mol} \%)^{13}$ and the presence of mannose has been taken to indicate the presence of non-mucin contaminants. It has recently been shown, however, that mucins contain small numbers of $N$-linked mannose-containing oligosaccharide chains ${ }^{14}$ and the presence of a putative mannosecontaining link glycopeptide has been reported by Forstner's group. ${ }^{13}$

The elution profile of the ion exchange gel used in this study is likely to differ to some extent from that of the DEAE-cellulose, discontinuous gradient system used in the previous studies, but this seems unlikely to account for the almost complete lack of mucin eluting at $<0.15 \mathrm{~mol} / \mathrm{l}$ $\mathrm{NaCl}$ when the high molecular weight fraction $\mathrm{A}$ was subject to ion exchange chromatography. Furthermore, the ion exchange profile reported here is closely similar to those reported by LaMont and Ventola for rat colonic mucin, ${ }^{3}$ Cope and colleagues for ${ }^{3} \mathrm{H}$ glucosamine labelled human colonic mucin, ${ }^{4}$ and also by Shimamoto and colleagues who used DEAE-cellulose with a discontinuous salt gradient and found that $92 \%$ of non-neoplastic human colonic mucin eluted at or above $0.15 \mathrm{~mol} / 1 \mathrm{NaCl} .{ }^{15}$

It could reasonably be argued that the use of antimucin monoclonal antibodies in a detection system could result in some mucin subclasses failing to be detected, and for this reason we developed the enzyme linked lectin binding assay using binding to wheat germ agglutinin, which binds to both sialic acid and $N$ acetylglucosamine, as a non-specific detection system. Mucins contain many $N$ acetylglucosamine residues and are still bound by wheat germ agglutinin (non-succinylated) after desialylation, ${ }^{16}$ so it is unlikely that mucins with shorter non-sialylated oligosaccharide side chains would have escaped detection using this system. The validity of this system is further supported by the similar elution profiles that are obtained when radiolabelled $N$-acetylglucosamine is incorporated into the mucins during tissue culture and detected by scintillation counting of the ion exchange chromatography fractions.

It is not possible to reach a definite conclusion about the reasons for the differences between the results of continuous gradient ion exchange chromatography of mucins as reported here and the discontinuous gradient ion exchange chromatography previously reported. We think, however, that the most likely explanation of the previously reported selective mucin subclass IV depletion is that this subclass contained a high proportion of the total mucin and that the glycoprotein eluting at a lower salt concentration probably included other components of mucus such as the concanavalin A reactive membrane components that have been shown to be shed with mucus. ${ }^{17}$ It is not surprising that most of the colonic mucin requires a relatively high salt concentration for elution on ion exchange chromatography since it is likely to be highly charged as a result of its extensive sialylation and sulphation. Depletion of subclass IV could then be explained simply as reflecting the total mucin depletion that is a hallmark of ulcerative colitis. This would explain the apparent discrepancy between the ion exchange profile of mucins obtained from homogenised tissue and that obtained from mucin secreted during tissue culture where no selective depletion of subclass IV was found in ulcerative colitis. ${ }^{18}$

The techniques for purification and analysis of 
Optical density read at $492 \mathrm{~nm}$

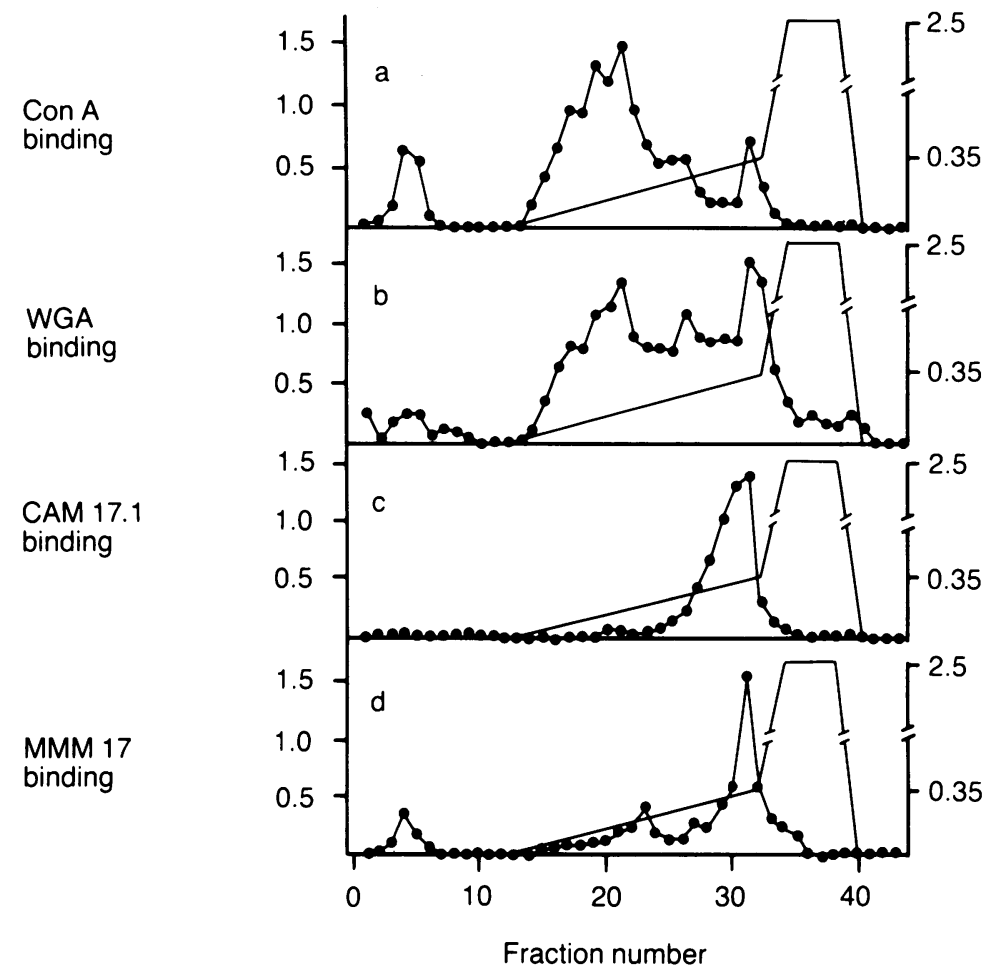

Figure 6: Ion exchange chromatography of a lower molecular weight glycoprotein (fraction $B$, see Fig 1) analysed by (a) concanavalin A binding; (b) wheat germ agglutinin binding; (c) CAM 17.1 antimucin monoclonal antibody binding; and (d) MMM 17 antimucin monoclonal antibody binding.

mucus glycoproteins reported here are applicable to all intestinal mucosae and allow rapid non-destructive analysis of mucins obtained from biopsy samples. A mucin sample can be purified and fractionated in three hours compared with at least four days using conventional

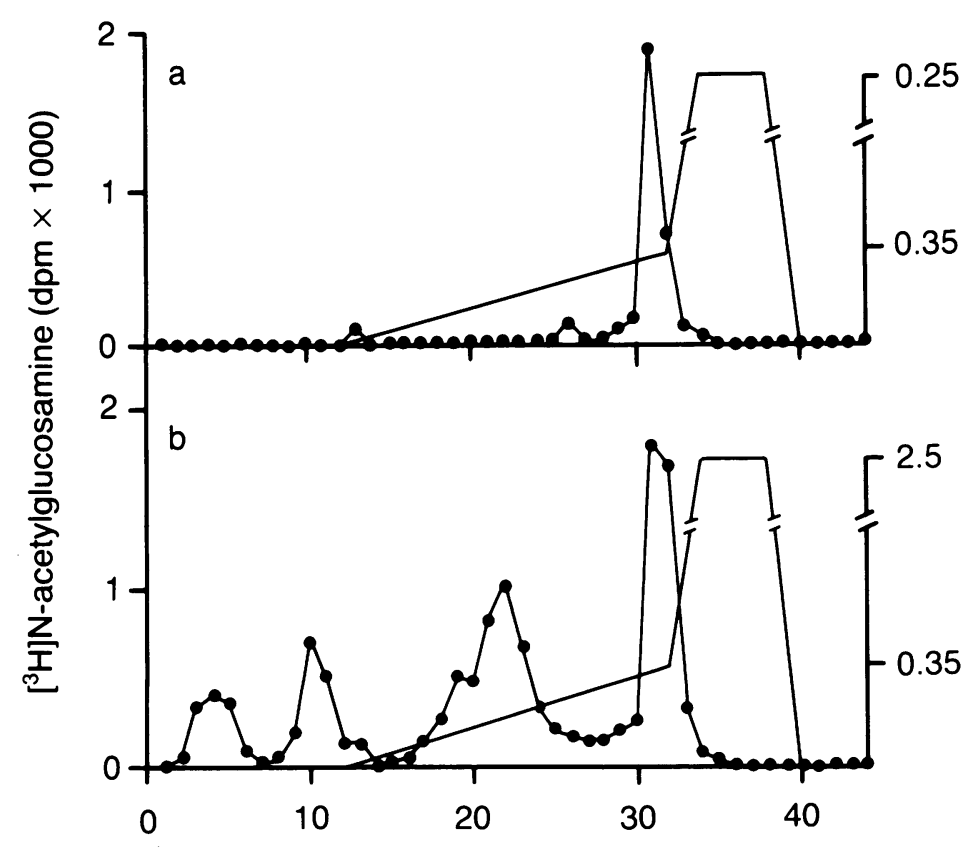

Fraction number

Figure 7: (a) Ion exchange chromatography of purified normal rectal mucus glycoprotein (fraction A, see Fig 4) after 24 hour tissue culture in medium containing $\left({ }^{3} H\right) \mathrm{N}-$ acetylglucosamine. (b) ion exchange chromatography of lower molecular weight glycoprotein (fraction B, see Fig 4) extracted from the same normal rectal biopsy specimen as (a) after 24 hour tissue culture in medium containing $\left({ }^{3} \mathrm{H}\right) \mathrm{N}$-acetylglucosamine. low pressure chromatography and density gradient centrifugation. The enzyme linked lectin assays are highly sensitive $(>0.2 \mu \mathrm{g}$ mucin) and reproducible. The combination of these techniques makes comparative studies of mucus biochemistry in gastrointestinal disease much more feasible.

The lack of an identifiable alteration in the ion exchange profile of ulcerative colitis mucin certainly does not rule out the possibility that there may be an underlying mucus defect in this disease. A mucus hypothesis for colitis is particularly attractive since it could explain the distribution of colitis in the colon if the normal balance between mucus synthesis and its degradation by bacterially secreted enzymes were upset since the concentration of these enzymes is likely to rise from proximal to distal colon. ${ }^{1920}$ Mucus and mucosal glycoproteins are undoubtedly altered in ulcerative colitis as has been shown by a changed pattern of binding by monoclonal antibodies ${ }^{21}{ }^{22}$ and by lectins, ${ }^{23-25}$ by the shortening of their oligosaccharide side chains, ${ }^{26}$ and by the reduced $O$-acetylation of the mucin sialic acids. ${ }^{27}$ Further studies are required to determine whether any of these alterations are fundamental to the disease and to assess their functional consequences.

This work was supported by grants from the Mersey Region Health Authority and the National Association for Colitis and Crohn's Disease (UK). DI and SR were W E C Knott research fellows of the British Digestive Foundation.

1 Podolsky DK, Isselbacher KJ. Composition of human colonic mucin. Selective alteration in inflammatory bowel disease. 7 Clin Invest 1983; 72: 142-53.

2 Podolsky DK, Isselbacher KJ. Glycoprotein composition of colonic mucosa. Specific alterations in ulcerative colitis Gastroenterology 1984; 87: 991-8.

3 LaMont JT, Ventola AS. Purification and composition of colonic epithelial mucin. Biochim Biophys Acta 1980; 626: 234-43.

4 Cope GF, Heatley RV, Kelleher J, Axon ATR. In vitro mucus glycoproteins production by colonic tissue from patients with ulcerative colitis. Gut 1988; 29: 229-34.

5 Filipe MI, Dawson I. The diagnostic value of mucosubstances in rectal biopsies from patients with ulcerative colitis and in rectal biopsies from patients with

6 Rhodes JM, Parker N, Ching CK, Patel P. Mucin subclasses in ulcerative colitis. Gastroenterology 1987; 93: 435-7.

7 Gahmberg CG, Hakomori S. External labelling of cell surface galactose and galactosamine in glycolipid and glycoprotein of human erythrocytes. F Biol Chem 1973; 248: 4311-7.

8 Ching CK, Rhodes JM. Enzyme-linked PNA lectin binding assay compared with $\mathrm{Ca} 19.9$ and CEA radioimmunoassay as a diagnostic blood test for pancreatic cancer. $\mathrm{Br} \mathcal{F}$ Cancer 1989; 59: 389-96.

9 Ugelstad J, Soderberg L, Berge A, Bergstrom J. Monodisperse polymer particles - a step forward for chromatography. Nature 1983; 303: 95-6.

10 Peterson GL. A simplification of the protein assay method of Lowry et al which is more generally applicable. Anal Biochem 1977; 83:346-56.

11 Makin CA. Monoclonal antibodies raised to colorectal carcinoma antigens. Ann $R$ Coll Surg Engl 1986; 68: 298-

12 MacDermott RP, Donaldson RM, Trier JS. Glycoprotein synthesis and secretion by mucosal biopsies of rabbit colon and human rectum. $\mathcal{F}$ Clin Invest 1974; 54: 545-54.

13 Roberton AM, Mantle M, Fahim REF, Specian RD, Bennick A, Kawagishi S, et al. The putative 'link' glycopeptide associated with mucus glycoproteins. Composition and properties of preparations from the gastrointestinal tracts of properties of preparations from the gastrointesting

14 Dekker J, Van Beurden-Lamers WMO, Strous GJ. Biosynthesis of gastric mucus glycoprotein of the rat. $\mathcal{F ~ B i o l}$ Chem 1989; 264: 10431-7.

15 Shimamoto C, Deshmukh GD, Rigot WL, Boland CR Analysis of cancer-associated colonic mucin by ion-exchange chromatography: evidence for a mucin species of lower molecular weight and charge in cancer. Biochim Biophys Acta molecular weight

16 Ching CK, Rhodes JM. Purification and characterization of a peanut-agglutinin-binding pancreatic-cancer-related serum peanut-agglutinin-binding pancreatic-cancer-related

17 LaMont JT, Ventola A. Synthesis and secretion of colonic glycoproteins. Evidence for shedding in vivo of low molecular weight membrane components. Biochim Biophys Acta 1980; 629: 553-65. 
18 Smith AC, Podolsky DK. Biosynthesis and secretion of human colonic mucin glycoproteins. $f$ Clin Invest 1987; 80: 300-7.

19 Miller RS, Hoskins LC. Mucin degradation in human colon ecosystems. Fecal population densities of mucin-degrading bacteria estimated by a 'most-probable number' method. Gastroenterology 1981; 81: 759-65.

20 Rhodes JM, Black RR, Gallimore R, Savage A. Histochemical demonstration of desialation and desulphation of normal and inflammatory bowel disease rectal mucus by faecal extracts. Gut 1985; 26: 1312-8.

21 Podolsky DK, Fournier DA. Emergence of antigenic glycoprotein structures in ulcerative colitis detected through protein structures in ulcerative colitis detected through

22 Podolsky DK, Fournier DA. Alterations in mucosal content of colonic glycoconjugates in inflammatory bowel disease defined by monoclonal antibodies. Gastroenterology 1988; 95: 379-87.

23 Boland CR, Lance P, Levin B, Riddell RH, Kim YS.
Abnormal goblet cell glycoconjugates in rectal biopsies associated with an increased risk of neoplasia in patients with ulcerative colitis: early results of a prospective study. Gu 1984; 25: 1364-71.

24 Jacobs LR, Huber PW. Regional distribution and alterations of lectin binding to colorectal mucin in mucosal biopsies from controls and subjects with inflammatory bowel disease. $\mathcal{F}$ Clin Invest 1985; 75: 112-8.

25 Rhodes JM, Black RR, Savage A. Altered lectin binding by colonic epithelial glycoconjugates in ulcerative colitis and Crohn's disease. Dig Dis Sci 1988; 33: 1359-63.

26 Teague RH, Fraser D, Clamp JR. Changes in monosaccharide content of mucus glycoproteins in ulcerative colitis. $B M \mathcal{F}$ $1973 ; 2: 645-6$.

27 Culling CFA, Reid PE, Dunn WL. A histochemical comparison of the $\mathrm{O}$-acetylated sialic acids of the epithelial mucins in ulcerative colitis, Crohn's disease and normal controls. f Clin Pathol 1979; 32: 1272-7. 